\title{
La traducción
}

como perversión

en la creación-

recreación de la

obra de teatro

En Marge! - jAl

Margen!

Licenciada y doctora internacional en traducción e interpretación por la Universidad de Alicante, donde actualmente ejerce como docente. Es traductora jurada de francés, másTranslation as perversion in the creation-recreation of the play En Marge! - Al Margen!

Paola Carrión González Jesús Belotto ter en Traducción Literaria, máster TILDE y máster en Profesorado. Su línea de investigación se centra en la traducción literaria, aunque también abarca otros ámbitos como la fraseología y la traducción jurídica. Contato: paola.carrion@ua.es Espanha

Es doctor en Traducción. Trabaja como profesor de español en Francia. Es autor del poemario breve Una luz de relámpagos (2010) y de las obras L'ambassadeur russe (2017) y En Marge! (2018). Ha traducido a poetas como Baudelaire y Anna Ruotolo.

Contato: jesus.belotto-martinez@ univ-rouen.frr

França 
PALABRAS CLAVE: teatro del absurdo; metateatralidad; traducción teatral; traducción colaborativa; culturema.

KEYWORDS: theatre of the absurd; meta-theatricality; theatre translation; collaborative translation; cultureme.
Resumen: El presente artículo, a cargo del autor español de la obra francófona En Marge! y la responsable de su traducción al español, pretende analizar los recursos de creación y recreación de una obra de teatro en un contexto de diglosia lingüística. En este sentido, evocaremos diferentes hitos de la reflexión traductológica en torno a la traducción teatral y analizaremos algunas de las estrategias seguidas a la hora de traducir iA/ Margen! al polisistema cultural español en el marco de un proyecto de traducción colectiva en el grado de Traducción e Interpretación de la Universidad de Alicante.

Abstract: The present paper by the Spanish author of the Frenchwritten theatre play En Marge! and the professor in charge of its collaborative translation into Spanish, aims to analyze the creation and recreation resources of a play in a diglossic context. In this sense, we will evoke different key aspects regarding critical reflexion around theatre translation and we will analyze some strategies followed throughout the iA/ Margen! translation process into the Spanish cultural polysystem. This project has been developed in the framework of a collaborative translation in the studies of Translation and Interpreting at the University of Alicante 
La traducción COMO Perversión en la Creación-ReCreación de la obra de teatro EN MARGE! - jAL MARGEN! Paola Carrión GonzÁlez

Jesús Belotto

\section{GÉNESIS DE UNA OBRA AL MARGEN Y SU TRADUCCIÓN}

En Marge! es una obra de teatro en tres actos y un epílogo escrita en el verano de 2017 y puesta en escena en junio de 2018 en el departamento de ultramar francés de Mayotte. Originalmente concebida y representada en francés, la pieza fue publicada de manera independiente por la compañía de teatro amateur Atomos Libros con una tirada de 200 ejemplares, acompañada de un texto híbrido titulado Poesias IV o para interpretar al margen. El conjunto de estos dos escritos sería traducido en el curso 2019-2020 por el alumnado de la asignatura Traducción Literaria Avanzada A-B/B-A: español-francés/francés-español, materia optativa del Grado de Traducción e Interpretación ofertado por el departamento homónimo de la Universidad de Alicante, en el marco de un proyecto pedagógico colaborativo auspiciado por la profesora Autor/a y respaldado por el Instituto de Ciencias de la Educación de dicha universidad por su encuadre dentro de una red para la mejora de la calidad docente, y que desembocará en el año 2021 en la publicación de un volumen bilingüe a cargo del Servicio de Publicaciones de la UA.

En lo que se refiere a la obra, la acción tiene lugar en un Centro Psiquiátrico imaginario de la isla de Mayotte, en el sudoeste del Océano Índico. Perteneciente geográficamente al archipiélago de Comoras, Mayotte votó en referéndum en el año 1976 su rechazo a la independencia de la potencia colonizadora francesa, contrariamente a las otras tres islas del archipiélago (Gran Comora, Mohéli y Anjouan), que hoy conforman la Unión de las Comoras, uno de los países más inestables políticamente y con mayor desigualdad social del mundo. Se trata pues de un huis clos que 
pone en escena a cinco personajes, un doctor en psiquiatría recién llegado al centro y cuatro pacientes con diversos desórdenes mentales - indicados visiblemente como elementos de vestuario según el código asignado en el Manual Diagnóstico y Estadístico de los Trastornos Mentales - para tejer una trama de metáforas encadenadas y juegos de espejos en torno a las desigualdades y violencias (si se nos permite el pleonasmo) de la realidad social de este territorio europeo ultraperiférico.

El ABSURDO EN TRAMPANTOJO: ESTRATEGIAS DE (DES)LOCALIZACIÓN DE LA OBRA

¡Al Margen!, que carece de cualquier rasgo futurista, se ubica sin embargo de forma explícita en el año 6222. Dicha fecha, que no sabría justificarse únicamente en un homenaje apenas velado a la novela 2666 de Roberto Bolaño, sitúa al lector en un espacio temporal improbable e incluso absurdo, y alejaba en apariencia a los espectadores que vieron la obra en Mayotte de su propia realidad social y vital. No obstante, las referencias (a menudo contingentes o indirectas) a acontecimientos e instituciones locales contemporáneos de la escritura y puesta en escena son constantes en la obra. El personaje de Nathalie, por ejemplo, se presenta como superviviente del naufragio de un kwassa-kwassa, endebles embarcaciones de pesca que los comorenses utilizan para entrar de forma irregular en Mayotte surcando los $70 \mathrm{~km}$ de océano que separan la costa de Anjouan de la pequeña isla francesa, y que se cobran cada ańo varios centenares de víctimas. 


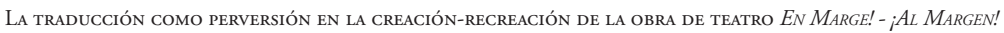
Paola Carrión GonzÁlez

En este sentido, tampoco es casual el empleo de términos tomados directamente del mahorés, dialecto de la lengua comorense derivada principalmente del swahili, y lengua materna de los habitantes del centro y el sur de Mayotte (los oriundos del norte de la isla hablan kibushi, derivada del malgache). De este modo, si la presencia de algunos de estos términos en la obra, empleados a menudo también en la isla para la comunicación francófona, obedecen a intenciones de localización geográfica o comicidad (verbigracia, las mabawas o alitas de pollo a la brasa o el bangué o marihuana), otros como el de sousou (prostituta) responden a un objetivo de denuncia de desigualdad social. Asimismo, el personaje del Director del centro (en realidad, un paciente disfrazado) cierra el primer acto con un monólogo en el que explica al Doctor Câlin (Lacan, en la versión española) cómo referirse a los comorenses en situación irregular como 'bonitos' (pouéré en lengua mahoresa, en referencia a los túnidos) permite, mediante un simple procedimiento de etiquetado y descalificación, restar importancia a la dramática situación de este colectivo: los citados naufragios, pero también explotación laboral, persecuciones, desahucios y conflictos raciales, expulsiones masivas, y las infinitas trabas burocráticas que agravan dichas situaciones de desigualdad y provocan un desbordamiento de facto de las instituciones y servicios a la ciudadanía, apenas paliados por una planificación social y unas inversiones públicas sempiternamente insuficientes.

En resumidas cuentas, la identificación por parte del espectador del espacio escénico (la representación de Mayotte en un futuro remoto) con el espacio en el que él mismo se sitúa (el Mayotte de 2018) posee una 
intención innegable de denuncia social, al mismo tiempo que incide en el carácter endémico de las problemáticas señaladas al plantear la posibilidad de su perdurabilidad en un lejano porvenir. El artificio temporal cumple pues aquí la función opuesta a la que declara; el propio autor, en una suerte de entrevista a sí mismo a la manera de Ionesco incluida en el texto que acompaña a la obra, no oculta la ironía de su juego: 'Señor Autor/a, ¿cuál es la relación entre su obra y la realidad de Mayotte? Ninguna, por supuesto. Es solo una distopía, una obra de ficción. Pueden dormir en paz.' (Poesias $I V)$. En el tiempo de la representación, el mapa es indisoluble del territorio.

MetateATRALIDAD Y APROPIACIONISMO COMO RECURSOS DE CREACIÓN DRAMÁticA

Desde la nota liminar, titulada "La república al margen" en una alusión más directa si cabe al partido La República En Marcha del presidente francés Emmanuel Macron, el autor repasa algunas de las influencias que más han marcado la obra. En un plano más concreto, parece evidente que ¡Al Margen! bebe principalmente de tres obras de autores eminentemente cercanos entre sí: Rinoceronte de Eugène Ionesco, El balcón de Jean Genet y El cementerio de automóviles de Fernando Arrabal. La terna conformada por dichas obras, encuadradas por la crítica en el teatro del absurdo, el teatro de la crueldad y el teatro pánico respectivamente, comparte entre sí y con la obra que nos ocupa multitud de características que no corresponde al presente artículo estudiar, sino que centraremos nuestra reflexión en otros dos elementos de creación: la metateatralidad y el apropiacionismo. 
La traducción COMO Perversión en la Creación-ReCreación de la obra de teatro EN MARGE! - jAL MARGEN! Paola Carrión González

A este respecto, resulta revelador analizar el texto que acompaña en su publicación a la obra ;Al Margen! Conviene pues empezar notando que Poesías IV entronca directamente, tanto por su título como por su estructura y composición, con las dos plaquettes homónimas (Poesías I y II) del poeta francés Isidore Ducasse, nacido en Montevideo en 1846 y muerto en París en 1970, y más conocido por el nombre de pluma de Conde de Lautréamont con el que firmó su obra mayor, los Cantos de Maldoror. En sendas obras del escritor francés, pero principalmente en las Poesías, Lautréamont/Ducasse acudía a procedimientos de creación poética tales como el pastiche y el autopastiche, el collage o patchwork literarios, la reescritura, la perversión o la inversión de citas y extractos de textos ajenos de toda índole (desde máximas de Pascal o Vauvenargues hasta réplicas dramáticas de Shakespeare o artículos enciclopédicos o periodísticos). Así, en esta continuación metapoética de la obra ducassiana, el autor de ;Al Margen! y Poesías IV recurre también al apropiacionismo y al plagiarismo en la escritura de sendos textos, insertando extractos con mayores o menores modificaciones de escritores como Aimé Césaire, Alain Ginsberg, Augusto Boal, Gertrude Stein, Samuel Beckett, Margaret Atwood o, una vez más, Eugène Ionesco, así como citas pertenecientes a la propia obra que acompańa; citas que, en algunos casos, eran ya en sí citas, abundando en la concepción poética ducassiana del autor de que 'El teatro ha de hacerse por todos' (Poésies IV).

Pero la dimensión metaliteraria de la obra se explicita desde el comienzo por la presencia misma del personaje de Ionesco, en realidad una antigua estudiante universitaria de teatro; por lo demás, autora de una tesis sobre 
el teatro del absurdo en Mayotte, en lo que supone un evidente elemento de autorreferencialidad y puesta en abismo metateatral. Pero también el plagiarismo y el apropiacionismo, en tanto en cuanto elementos constituyentes de la escritura no solo de Poesías IV sino de la propia ¡Al Margen!, vienen a incidir en la dimensión de metateatro de la que hace gala la obra. Así, por poner solo algunos ejemplos, el autor retoma en el primer acto la famosa sentencia de Huis Clos de Jean-Paul Sartre, 'el infierno son los otros', cuando el personaje de Ionesco dice de la celda de aislamiento que 'es el infierno, sin los otros'. Del mismo modo, los personajes de Ionesco y Nelly interpretan un extracto cuasi literal de la "Entrevista del Trascendente Sátrapa Ionesco a sí mismo", texto del dramaturgo francorrumano recogido en su ensayo antológico Notas y contra-notas (1962). Esta enésima puesta en abismo (meta) teatral revela abiertamente su fuente original, tanto en la didascalia que introduce este fragmento de la obra como en la réplica posterior en que Nelly, una vez terminada la escena dentro de la escena, muestra su asombro al comprobar que, efectivamente, el personaje de Ionesco conoce palabra por palabra todas las entrevistas dadas por el auténtico Ionesco.

A continuación, analizaremos de manera sucinta el estado de la cuestión de la reflexión en torno a la traducción teatral, un tipo de traducción cuya complejidad "no deriva sólo de la resolución del potencial diferendum entre un ego y un alterego de naturaleza lingüístico-cultural, sino también del imperativo de manipular simultáneamente dos códigos, el texto y su camaleónica concreción representacional, vinculados por relaciones de mutua determinación" (Prodan, 2005, 88), para después centrarnos en algunas de las 
La traducción COMO Perversión en la Creación-ReCreación de la obra de teatro EN MARGE! - jAL MARGEN!

estrategias seguidas por el alumnado de la asignatura de Traducción Literaria avanzada de la Universidad de Alicante a la hora de traducir ;Al Margen!

LA TRADUCCIÓN TEATRAL COMO EXPRESIÓN CREATIVA DE TRANSFERENCIA CULTURAL

Disponía Larra ya en el primer tercio del siglo XIX unos fundamentos ineludibles para la práctica de la traducción teatral: saber qué tipo de teatro se está traduciendo, conocer teatro y público tanto de la lengua origen como de la lengua meta, saber leer ambas lenguas y por supuesto, saber escribirlas. Decía: “Todo eso se necesita, y algo más, para traducir una comedia, se entiende, bien; porque para traducirla mal no se necesita más que atrevimiento y diccionario: por lo regular, el que tiene que servirse del segundo no anda escaso del primero" (Larra, 1836).

La reflexión en torno a la traducción teatral o dramática llega tardía con respecto a su práctica, mucho más tardía en tanto en cuanto lo hacen las primeras obras teatrales, de entre veinticinco y veintiséis siglos de edad. Si bien se atisban ciertas consideraciones sobre esta cuestión a finales del siglo XVIII, hasta 1980 no comienza el verdadero auge de la traducción teatral (Lapeña, 2014). Un tipo de traducción que durante décadas - o incluso decalustros y siglos - proliferó más que la propia producción de teatro endógeno, llegando los carteles de teatros nacionales a llenarse de títulos de obras teatrales extranjeras traducidas al español en mucha mayor medida de lo que lo hacían nuestros títulos originales. Algo que suscitó el interés y la sorpresa de teóricos que no veían equilibrado este crecimiento exponencial 
del teatro traducido con respecto al avance analítico de reflexión teórica de tal actividad: "Es como si durante trescientos años se hubieran estado fabricando motores y nadie hubiese escrito un solo tratado de mecánica general” (Santoyo, 1995, 14). Así pues, el estudio de la traducción dramática no parece partir de un marco teórico que establezca la especificidad del ámbito o consolide unos principios sobre los que puedan gravitar los análisis concretos de traducciones concretas de obras concretas, sino que este último escenario nos invita a educir unas conclusiones que puedan conformar una teoría de la traducción teatral.

A este respecto, cabe mencionar ejemplos contemporáneos dedicados a la dramaturgia como el ya desaparecido escritor, traductor, actor, director y teórico - entre otros - Jaume Melendres, quien "como teórico de teatro, lógicamente también reflexionó sobre la tarea misma de la traducción teatral" (Sala, 2010, 314) y defendía la idea de la no existencia de unas características específicas de la traducción teatral, por la singularidad de cada obra. Una posición contraria a muchos estudiosos que encontraron su piedra angular en la obra "Translation Studies" de Susan Bassnett, quien reconocía la especificidad del texto teatral:

even the most superficial consideration of the question must show that the dramatic text cannot be translated in the same way as the prose text. To begin with, a theatre text is read differently. It is read as something incomplete [...] since it is only in performance that the full potential of the text is realized $(1980,120)$. 


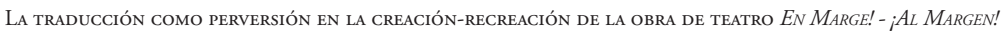
Paola Carrión GonzÁlez

Llámese circunloquio, llámese “empezar la casa por el tejado". En cualquier caso, la práctica nos deja ejemplos comparables a otros ámbitos del arte de la traducción, teniendo en cuenta la particularidad (con)textual de cada caso.

Sea como fuere, la necesidad de traducir teatro se antoja aquí como un medio de transmisión - reivindicación - cultural de la sociedad, que combina movimientos realistas, populares, clásicos, costumbristas con el elemento absurdo que articula la obra aquí presentada. Este último elemento colisiona con el clasicismo teatral haciendo de la sátira el instrumento de descripción social que nos presenta de manera evidente el hecho denunciado bajo formas disparatadas y aparentemente ficticias. Y la referencia caricaturizada, como eje vertebrador y escollo en la traducción, la realidad cultural de difícil transmisión que conforma la temática principal, objetivo primordial, detonante entre el público, en su búsqueda por la reacción exacta.

En torno a la traducción teatral surgen inevitables cuestiones: ¡cómo traducir la teatralidad? ¿Cómo reproducir su impacto en una audiencia cultural distinta? ¿Cómo trasladar a otro sistema lingüístico el proceso creativo que consigue tales fines? En una de sus obras fundamentales, Susan Bassnett nos describe distintas estrategias o métodos en la traducción teatral: "Treating the theatre text as a literary work, [...] Using the SL cultural context as a frame text, [...] Translating 'performability', [...] Creating SL verse drama in alternative forms, [...] Cooperative translation" $(1985,90)$. Para esta autora, la dificultad más relevante de la traducción teatral es trasladar al plano escrito un texto que forma parte de un sistema mucho más amplio, que incluye signos kinésicos y paralingüísticos, es decir, reproducir el elemento gestual. Habida cuenta de estos 
aspectos, se suma una reorientación de las teorías tradicionales ${ }^{1}$ de traducción, influenciadas por el impacto de la teoría de la manipulación y la teoría de los polisistemas (Bassnett, 1991). Esta última nos descubre un dinamismo que determinará unas estrategias que se escapan de la literalidad para descubrir nuevas perspectivas en el tratamiento de sistemas en contacto.

El elemento gestual de Bassnett nos traslada a una cuestión inexorable en traducción teatral: traducir para ser leído, traducir para ser interpretado. A este respecto, Santoyo introduce toda una serie de conceptos afines a cada una de esas dos variantes; así, la traducción para ser leída - readeroriented - nos llevaría a términos como la traducción - directa, indirecta, completa, etc. - o la transliteración - interlineal y paralela -, mientras que la traducción para ser interpretada-performance-oriented-plantearía una senda marcada por el traslado - versión o adaptación (readaptación) - y la reescritura - posible recreación -, desembocando ambas trayectorias en la transposición escénica. Por su parte, el plagio y la recomposición textual no responderían aquí "a método ni a proceso alguno de transferencia intertextual, semiológica o interlingüística” (Santoyo, 1989, 108), por lo que escaparían al plano de la traducción.

Lejos de querer imponer un modus operandi traductivo, la funcionalidad del texto ha de primar sobre su literalidad en cuanto al original. Que el resultado funcione en escena, esto es, provocar en el público la reacción de la

1 Según Santoyo, la traducción literal o "traslado" aquí solo tendría cabida como paso previo a la traducción final. Cabría hablar de adaptación, siempre que fuera "a un nuevo código cultural”, por el "peligro que entrańa que los bucaneros teatrales lo utilicen como patente de corso para disfrazar todo tipo de inaceptables manipulaciones, textuales y escénicas" (1989, 103). 
La traduCCión COMO PERVERSión EN LA CREACión-RECREACión de LA ObRa de TEATro EN MARGE! - ¡AL MARGEN! Paola Carrión González

obra original ${ }^{2}$. Todo lo demás son convenciones lingüísticas y estilísticas que cabría respetar en la medida en que lo permita tal funcionalidad. Al menos, esta ha sido la máxima y principal estrategia para la concepción de nuestra traducción, considerados la naturaleza y propósito singulares del original.

\section{INTERFERENCIAS CULTURALES, RECREACIONES Y PERVERSIONES TRADUCTIVAS}

La traducción teatral - como en otros muchos casos de textos literarios ricos en referencias culturales - encuentra su esencia en el discernimiento de la transcreación más que en la traducción tradicionalmente concebida. Entran aquí en juego conceptos ya mencionados relacionados con la adaptación, versión, (re)creación o incluso "perversión” traductiva. Así, son numerosos los elementos que bañan el texto de un carácter a priori intraducible, total o relativo, que van desde la oralidad hasta los "culturemas"3 o "realia" (Vlahov \& Florin, 1970) más arraigados. Y es que, aunque casi toda traducción está condicionada, el nivel de exigencia cultural y referencial del texto origen nos sitúa en los límites de la aceptabilidad de lo que es o no es una traducción, o de cuándo una traducción sufre un proceso de recreación tan agudo que

2 Esta norma no escrita, ha suscitado la controvertida perspectiva de la retraducción de los clásicos, una adaptación de las traducciones canónicas a la realidad cultural del momento, criticada por muchos, alabada por otros. En este sentido, no solo cabe aludir al envejecimiento de la lengua en las traducciones realizadas, también es justo reconocer que la retraducción "produce uno de los factores que diferencian la obra clásica original y la obra clásica traducida: mientras la primera, la obra original, tiene una textualidad única, la versión traducida de la misma tendrá tantas cuantas veces haya sido traducida" (Vega, 2005, 9).

3 Analizados bajo esa apelación y otras tantas por Nida, Newmark, Vermeer \& Nord, Luque, Molina, Mangiron, Santamaría, Carbonell, por citar algunos. 
acaba convirtiéndose en perversión, siempre en el mejor sentido de la palabra. En otras palabras, una traducción que rompa la euritmia circundante de la gracia literaria de la misma forma en que opera el original.

Volviendo a los cimientos sobre los que reposa el ejercicio de la traducción teatral, alejados de la esencia de la literalidad en tal trasvase lingüístico del hecho literario, cabe resaltar que se trata de "buscar el equivalente, no de las palabras, sino de las situaciones. [ ] Lo demás es ser un truchimán, sentarse en el agujero del apuntador y decirle al público espańol: «Dice monsieur Scribe», etc., etc." (Larra, 1836), partiendo de la base de que la equivalencia ha de ser, en circunstancias de evidente culturalidad, una equivalencia translémica, exclusiva en cada caso, en cada situación y fórmula textual, entendida como "una relación global, única e irrepetible para cada binomio textual y, por supuesto, para cada actuación traductora" (Rabadán, 1991, 51).

En Marge! (Autor/a, 2018) es un buen ejemplo de lo opuesto a la jitanjáfora, pues el valor estético de muchos fragmentos se sacrifica por el sentido de las secuencias textuales que lo componen. Podría ser considerado el "antihéroe" de la sublimidad lírica, la hermana locuaz de la retórica que a voces depreca la realidad social que nos rodea. Elogio a la sustantividad - en este caso social en detrimento de la grandilocuencia estética clásica. Y eso es precisamente lo que se ha pretendido recrear con la traducción al español, una gran jitanjáfora que destripara una realidad de aparente raciocinio para presentar al público los despojos de una sociedad carente de humanidad, no sin transgredir sus formas primigenias. La historia, un grupo de aparentes "enfermos" psiquiátricos, afectados por múltiples patologías - de objetividad subjetiva-, 


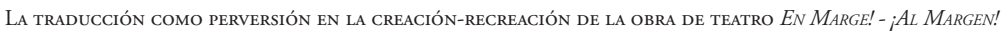

encerrados en un manicomio en la pequeńa isla de Mayotte. Un marco que nos presenta no solo una especificidad lingüística única sino también la encarnación de la singularidad isleña representada en una problemática migratoria que sumerge a la obra en un contexto social que era preciso denunciar. La protagonista, una libertad que varía según la perspectiva, como la ilusión del taumatropo evocado entre líneas, que se oculta tras la falta de misericordia de algunos de sus personajes, más reales que ficticios, todo ello verbalizado con la jerigonza del absurdo - interpretado por y para sus máximos representantes - plagada de galimatías lingüístico-culturales cuya traducción - perversión - se presenta a continuación. Así pues, indicamos un puñado de ejemplos ${ }^{4}$ de esas "perversiones" que nos hemos permitido realizar, nunca gratuitas, siempre queriendo respetar lo absurdo del teatro del absurdo:

\begin{tabular}{|c|c|c|c|}
\hline & Obra original & Pág. & Traducción al español \\
\hline (1) & $\begin{array}{l}\text { LE PLOMBIER portera un bleu } \\
\text { de travail blanc, un blanc de } \\
\text { travail, quoi }\end{array}$ & 16 & $\begin{array}{l}\text { EL FONTANERO llevará un } \\
\text { mono de trabajo blanco, muy } \\
\text { blanco, y muy mono, vamos }\end{array}$ \\
\hline (2) & Il ne faut pas écouter le $\mathrm{c}[\mathrm{h}] œ u r$ & 18 & $\begin{array}{l}\text { No hay que hacer caso al cor[o] } \\
\text { azón }\end{array}$ \\
\hline (3) & ... il dit que dalle & 19 & $\ldots$ no dice ni mo \\
\hline (4) & $\begin{array}{l}\text { NELLY. - Le fou du roi, un fou } \\
\text { furieux, un fou-rire... } \\
\text { IONESCO. - un je-m' en-fous } \\
\text { NELLY. - un fou à lier, un truc } \\
\text { de fous, un amour fou... } \\
\text { IONESCO. - ... une } \\
\text { foufounette... }\end{array}$ & 32 & $\begin{array}{l}\text { NELLY. - Melocotón, } \\
\text { locomotora, estafilococo. } \\
\text { IONESCO. - . ...hacerse el loco... } \\
\text { NELLY.-loco de atar, a lo loco, } \\
\text { loco de amor. } \\
\text { IONESCO. - ...cocoloco... }\end{array}$ \\
\hline
\end{tabular}

4 Para un análisis completo de los culturemas de la obra, consúltese Autor/a (2020). 


\begin{tabular}{|c|c|c|c|}
\hline & Obra original & Pág. & Traducción al español \\
\hline (5) & $\begin{array}{l}\text { Mais des sans papiers, ce ne sont } \\
\text { plus des personnes, ce sont des } \\
\text { clandestins. Mieux encore, des } \\
\text { clandos, car les diminutifs servent } \\
\text { à cela, à diminuer }\end{array}$ & 41 & $\begin{array}{l}\text { Pero, los ilegales, ya no son } \\
\text { personas, son clandestinos. O } \\
\text { mejor aún, sin papeles, porque } \\
\text { el "sin" significa eso, para indicar } \\
\text { que no son nada }\end{array}$ \\
\hline (6) & $\begin{array}{l}\text { On la transfère au CHM. Il vaut } \\
\text { mieux qu'elle crève là-bas, cela } \\
\text { nous évitera la paperasse }\end{array}$ & 44 & $\begin{array}{l}\text { La trasladaremos al Centro } \\
\text { Hospitalario de Mayotte. Es mejor } \\
\text { que la palme allí, nos ahorraremos } \\
\text { toda la burrocracia }\end{array}$ \\
\hline (7) & $\begin{array}{l}\text { Je fais une sortie, je fais une sortie } \\
\text { bateau, une sortie dauphins, } \\
\text { une sortie baleines, une sortie } \\
\text { dugongs, une sortie raie-mantas, } \\
\text { une sortie la raie de mon cul }\end{array}$ & 49 & $\begin{array}{l}\text { Que me voy de excursión, la del } \\
\text { barco, la de los delfines, la de las } \\
\text { ballenas, la de los dugongos, las de } \\
\text { los tiburones o la de mis cojones }\end{array}$ \\
\hline (8) & Allez vous faire braconner & 51 & Que te folle un pez espada \\
\hline (9) & $\begin{array}{l}\text { NELLY. - C'est du Morse! } \\
\text { IONESCO. - Un morse à } \\
\text { Mayotte? } \\
\text { NELLY. - Du code Morse, ducon } \\
\text { ! IONESCO. - Ah, un dugong, } \\
\text { c'est plus plausible }\end{array}$ & 63 & $\begin{array}{l}\text { NELLY. - ¡Es una Morsa! } \\
\text { IONESCO. - ¿Una morsa en } \\
\text { Mayotte? } \\
\text { NELLY. - ¡De código Morse, } \\
\text { tarugo! IONESCO. - Ah, un } \\
\text { besugo, eso es más creíble }\end{array}$ \\
\hline (10) & $\begin{array}{l}\text { Le théâtre doit être fait par tous ( ) } \\
\text { Le théâtre doit être fait partout ( ) } \\
\text { Le théâtre doit être fait partouze }\end{array}$ & 81 & $\begin{array}{l}\text { El teatro ha de hacerse }(\ldots) \text { El } \\
\text { teatro ha de hacerse por nosotros } \\
\text { (...) El teatro ha de hacerse } \\
\text { porno-sotros }\end{array}$ \\
\hline
\end{tabular}

Tabla 1. Ejemplos de transcreación en “¡Al Margen!”

Si nos adentramos en el análisis de la traducción de estos segmentos y siguiendo el enfoque funcionalista de Reiss (1971), de la skopostheorie de Vermeer (1978) - basado en la intencionalidad de la unidad comunicativa y de la funcionalidad dinámica de la teoría del polisistema (Even-Zohar, 1979), más centrada en una antropología de la traducción que contempla 
La traduCCión COMO PERVERSión EN LA CREACión-RECREACión de LA ObRa de TEATro EN MARGE! - ¡AL MARGEN! Paola Carrión González

como eje fundamental las relaciones interculturales, observamos que las traducciones aquí propuestas son fruto de una reflexión - más o menos acertada - del elemento cultural tanto de la lengua de partida como de llegada, en su vertiente más lingüística. Así, obviadas las referencias políticas que en el texto origen se hacen a declaraciones lapidarias de figuras políticas como Sarkozy o Macron, la existencia de elementos culturales en lengua shimaoré o fragmentos en los que la utilización de equivalentes obtiene la funcionalidad deseada sin grandes alteraciones del texto de partida ${ }^{6}$, vemos algunos casos en que la creación es necesaria si se desea obtener en la traducción el mismo efecto o parecido que en el original, especialmente en segmentos que contienen juegos de palabras o rimas irreproducibles en el texto final con los mismos componentes lingüísticos, a todo lo cual se suma el componente idiomático de la fraseología. De esta suerte, vemos como el bleu de travail [1] que en español correspondería a un 'mono de trabajo' no encierra en la lengua de destino un color específico con el cual poder hacer un juego de palabras, que sí puede obtenerse si en lugar del color se juega con el significado del adjetivo. Ese mismo elemento idiomático

5 El autor utiliza palabras en lengua shimaoré como bangué, foundi, kwassa-kwassa o sousou que se explican, tanto en el original como en la traducción - donde son conservadas -, en un glosario al final de la obra, con el fin de evidenciar la especificidad diglósica de Mayotte.

6 En el caso de los equivalentes, cabe resaltar que en unos casos las modificaciones sufridas en la traducción no eran muy relevantes, pues la referencia empleada era compartida por ambas culturas: Vous avez acheté votre Diplôme à la Rue du Commerce ou quoi! (p. 53)/'‘ ¿Se ha comprado el título en Amazon o qué?' (cambio de empresa de venta online); pero en otros casos la transformación llegaba a los límites de la adaptación: Allez, allez, allez, réveillez-vous, mon dormeur du bal! (p. 22)/‘Vamos, vamos, vamos! ¡Despiértate, que la vida no es sueńo!' (cambio de referencia a Arthur Rimbaud por un título de sobra conocido de Calderón de la Barca). 
juega en contra de la literalidad en muchos de los ejemplos propuestos: la expresión que dalle que se transforma en 'no dice ni mo' [3] (en lugar de 'ni mu') para ganar un nuevo rompecabezas con el nombre de Momo, de quien se habla en ese diálogo; la serie de expresiones con la palabra fou (fou du roi, fou furieux, fou-rire, je-m'en-fous, fou à lier, truc de fous, amour fou, foufounette) completamente pervertida en el texto de llegada por su trivialidad semántica pero que sí mantiene una enumeración de unidades que contienen la palabra "loco"; los clandestinos (clandos) transformados en 'sin papeles' [5] al no existir en español una tradición de la abreviatura tan anclada como en francés o la transformación de ducon y dugong [9] por 'tarugo' y 'besugo' respectivamente, con el fin de mantener la situación de no entendimiento y proximidad fonética de los vocablos en juego. Por otra parte, pedimos perdón por no haber podido conservar el nivel de genialidad de algunos juegos de palabras - partouze por 'porno-nosotros' - así como por el registro vulgar empleado en los ejemplos [6] y [7] donde quisimos mantener tanto el tono crudo y soez del original como la rima fácil y la presencia de referentes marítimos. No obstante, hubo algún caso en que pudimos ganar algún juego de palabras - paperasse por 'burrocracia' [6] - o incluso donde el original permitía la traducción literal - $c$ [h]oeur por 'cor[o] azón' [2]-, aunque para nuestra desdicha y al tiempo gozo creativo nuestro, no fueron muchas las ocasiones.

Por otra parte, merece especial mención el concepto de la "retrotraducción" en esta obra, pues el propio autor utiliza algunos fragmentos literarios que sufren ligeras transformaciones en una primera traducción hacia el francés 


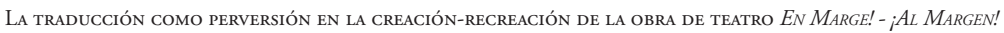
Paola Carrión GonzÁlez

Jesús Belotto

y que más tarde volverán a someterse a ciertos cambios, incluso siendo la lengua de llegada la misma que la lengua objeto de traducción en la pluma del autor. Tal es el caso del poema "Zurita” del chileno Raúl Zurita, que vuelve a su esencia al español con la transcripción de sus palabras originales, pero conservando la modificación del autor de la pieza teatral: Momo me dit que l'orage allait s'affaiblir (versión original de la obra teatral)/“Zurita me dijo que iba a amainar” (versión original del poema de Raúl Zurita)/'Momo me dijo que iba a amainar' (traducción final de la obra teatral). Si atendemos al concepto de fidelidad en la traducción, no sería este un caso de perversión al dramaturgo, sino al poeta. Algo parecido ocurre con la cita que abre la obra teatral, de Ascanio Celestini, traducida/recreada del italiano al francés por el autor de En Marge!, trasladada a su vez al español en jAl Margen!: À qui appartiennent les morts de la mer? (versión original de la obra teatral)/A chi appartengono i morti di Lampedusa? (versión original de Ascanio Celestini)/‘‘A quién pertenecen los muertos del mar?' (traducción final de la obra teatral). No hemos de olvidar que, en cualquier caso, la traducción teatral ya de por sí sufre diversas traducciones/interpretaciones internas, donde en ocasiones se desdibujan los límites de la creación en la traducción, así como el papel de la figura del traductor:

El traductor de teatro es el intérprete del intérprete [el actor], porque hace una interpretación de un texto para que sea interpretado posteriormente; $y$, precisamente porque es un intérprete que trabaja para otro intérprete que es un artista, el traductor también es un artista, o al menos debería serlo (Melendres, 2000). 


\section{CONCLUSIÓN}

Los fragmentos que hemos analizado son una muestra de algunos de los casos de transcreación más evidentes, donde el contexto, el registro, el estilo y tono del autor, así como el efecto expresivo final, prevalecen sobre la fidelidad semántica. La poética apropiacionista y recreadora que subyace a iAl Margen! y que, lo hemos visto, queda explicitada en el texto de Poesías IV o para interpretar al margen que acompaña a la publicación de la obra, así como la importancia del componente de denuncia social latente en cada escena, exigían a su vez de una poética de traducción recreadora a la hora de reescribir la pieza en español. Del mismo modo en que los locos resultan al final más cuerdos que los cuerdos en esta obra, la fidelidad de la traducción a su literariedad pasa definitivamente por la infidelidad a su literalidad. Así lo han entendido los responsables de su versión en español, erigidos, como exigía el texto original, en un grupo de disparatados transcreadores a la caza y captura de la funcionalidad escénica mediante la perversión - consentida de la pluma del autor.

\section{REFERENCIAS BIBLIOGRÁFICAS}

Bassnett, Susan. "Translating for the Theatre : The Case Agains Performability". In : TTR : traduction, terminologie, rédaction, vol. 4, nº 1, 1991, 99-111.

Bassnett, Susan (1985), "Ways through the Labyrinth: Strategies and Methods for Translating Theatre Texts". In: Hermans, Theo (ed.). The Manipulation of Literature. London: Croom Helm, 1985, 97-103.

Bassnett, Susan. Translation Studies. London: Routledge, 1980. 
La traduCCión COMO PERVERSión EN LA CREACión-RECREACión de LA ObRa de TEATro EN MARGE! - ¡AL MARGEN!

Even-Zohar, Itamar. "Polysystem Theory". In : Poetics Today, Special Issue: Literature, Interpretation, Communication, vol. 1, no 1/2. Duke University Press, 1979, 287-310.

González, Paola Acrrión. En Marge !, Mayotte, 2018.

González, Paola Acrrión. "Estrategias de traducción y elementos de inequivalencia interlingüística: la traducción teatral en el aula y los contrastes lingüísticos y culturales". In: Roig-Vila, R. (coord);; Antolí Martínez, J.M., Díez Ros, R., Pellín Buades, N. (eds.). Redes de Investigación e Innovación en Docencia Universitaria. Volumen 2020. Instituto de Ciencias de la Educación, Universidad de Alicante, 2020, 185-197.

Lapeña, Alejandro L. "Recalificar el páramo. Bases para un nuevo modelo traductológico de análisis del texto teatral". In: Sendebar. Revista de la Facultad de Traducción e Interpretación, no25, 2014, 149-172.

Larra, Mariano José. De las traducciones. In: El Español. Diario de las Doctrinas y los Intereses Sociales. Madrid, nº132, 11 marzo 1836.

Melendres, Jaume. "Traduir respiracions". In: IV Jornadas de Traducción en Vic: Traducción teatral. Universidad de Vic, abril 2000.

Prodan, Delia Ionela. "Dificultades de traducción inherentes al género dramático". In: Iliescu, Catalina (ed). Duplicitat comunicativa i complicitat creadora en la traducció del teatre. Alicante: Universidad de Alicante, 2005, 85-97.

Rabadán, Rosa. Equivalencia y traducción. León: Ediciones de la Universidad de León, 1991.

Sala Lleal, Jordi. "La traducción como expresión de la creatividad teatral". In: Estudis escènics: quaderns de l'Institut del Teatre de la Diputació de Barcelona. Ejemplar dedicado a: Jaume Melendres i Inglès (1941-2009), n³7, 2010, 310-322. 
Santoyo, Julio-César. "Reflexiones, teoría y crítica de la traducción dramática. Panorama desde el páramo español”. In: Francisco Lafarga, Roberto Dengler Gassin (coord..). Teatro y Traducción, 1995, 13-24.

Santoyo, Julio-César. "Traducciones y adaptaciones teatrales: ensayo de tipología". In: Cuadernos de teatro clásico. Ejemplar dedicado a: Traducir los clásicos, $\mathrm{n}^{\circ} 4$, 1989, 95-112.

Vega Cernuda, Miguel Ángel. "El reto de la traducción de los clásicos. Consideraciones de sociología literaria y traductiva”. In: Miguel Ángel Vega Cernuda, Juan Pedro Pérez Pardo (coord..). La traducción de los clásicos: problemas $y$ perspectivas. 2005, 1-10.

Vlahov, S., Florin, S. “Neperovodimoe v perevode. Realii”. In: Masterstvo perevoda, $n^{\circ}$ 6, Moskvà, Sovetskij pisatel', 1970, 432-456. 